\title{
Use of Fe-C Information as Reference for Alloying Effects on $B_{S}$
}

\author{
LINDSAY LEACH, PETER KOLMSKOG, LARS HÖGLUND, MATS HILLERT, \\ and ANNIKA BORGENSTAM
}

\begin{abstract}
Many empirical equations of the variation of the critical temperature with alloy content of the start of bainite formation in steels are available. They are often obtained by regression analysis of measured values for a large number of alloyed steels, usually with several alloying elements. However, such equations differ considerably, especially when applied to pure $\mathrm{Fe}-\mathrm{C}$ alloys, which results in large differences between reported effects of individual alloying elements since they have not been based on the $\mathrm{Fe}-\mathrm{C}$ system as a reference. Apparently, for the first time, an empirical equation is now derived by starting with information from $\mathrm{Fe}-\mathrm{C}$ alloys and low alloy steels and then adding the effect of each alloying element separately, using information from ternary Fe-C-M alloys. Sets of information from the same alloy content but different carbon contents proved particularly useful. Lines connecting such points are regarded as $B_{\mathrm{S}}$ lines for the respective alloy content and the effect of alloying elements was evaluated from their distance from the $B_{\mathrm{S}}$ line for $\mathrm{Fe}-\mathrm{C}$ alloys. Only under this condition can coefficients for alloying elements be expected to represent the physical effect of the elements. The resulting equation was tested with about 600 experimental $B_{\mathrm{S}}$ temperatures.
\end{abstract}

https://doi.org/10.1007/s11661-019-05371-1

(C) The Author(s) 2019

\section{INTRODUCTION}

BAINITE is one of the microstructures that can form from austenite on cooling. It has long been of considerable practical importance because it may prevent the complete transformation of austenite to martensite. On the other hand, a completely bainitic microstructure may have unique properties and has found practical use, especially in recent times. Alloying elements have been used for controlling the formation of bainite in various applications. Due to various aspects, it has thus been of considerable interest to be able to control the formation of bainite by alloying elements and information on their effects on the start temperature for bainite formation has been of central interest. The start temperature is denoted as $B_{\mathrm{S}}$ and the variation of the $B_{\mathrm{S}}$ temperature with the carbon content at fixed alloy content can be represented by a $B_{\mathrm{S}}$ line.

Several empirical equations for predicting the $B_{\mathrm{S}}$ temperature from the steel composition have been derived from large amounts of experimental information on alloyed steels. The result is usually presented as a linear equation with a coefficient for each element, often

LINDSAY LEACH, PETER KOLMSKOG, LARS HÖGLUND, MATS HILLERT, and ANNIKA BORGENSTAM are with the Department of Materials Science and Engineering, KTH Royal Institute of Technology, Brinellvägen 23, 10044 Stockholm, Sweden. Contact e-mail: annbor@kth.se

Manuscript submitted February 8, 2019.

Article published online August 5, 2019 obtained by regression analysis. An early example is the equation by Steven and Haynes ${ }^{[1]}$ who determined the $B_{\mathrm{S}}$ temperatures of a group of 65 steels and evaluated the coefficients by linear regression analysis.

$$
B_{\mathrm{S}}\left({ }^{\circ} \mathrm{C}\right)=830-270 \mathrm{C}-90 \mathrm{Mn}-37 \mathrm{Ni}-70 \mathrm{Cr}-83 \mathrm{Mo}
$$

The carbon and alloy contents are given in mass pct. In a recent review, Kang et al. ${ }^{[2]}$ listed nine, more recent equations, ${ }^{[3-11]}$

$$
B_{\mathrm{S}}\left({ }^{\circ} \mathrm{C}\right)=656-57.7 \mathrm{C}-75 \mathrm{Si}-35 \mathrm{Mn}-15.3 \mathrm{Ni}-34 \mathrm{Cr}-41.2 \mathrm{Mo}
$$

$$
\begin{gathered}
B_{\mathrm{S}}\left({ }^{\circ} \mathrm{C}\right)=718-425 \mathrm{C}-42.5 \mathrm{Mn} \\
B_{\mathrm{S}}\left({ }^{\circ} \mathrm{C}\right)=844-597 \mathrm{C}-63 \mathrm{Mn}-16 \mathrm{Ni}-78 \mathrm{Cr} \\
B_{\mathrm{S}}\left({ }^{\circ} \mathrm{C}\right)=720-582.63 \mathrm{C}+126.6 \mathrm{C}^{2} \\
-91.68 \mathrm{Mn}-66.34 \mathrm{Ni}-31.66 \mathrm{Cr} \\
-42.37 \mathrm{Mo}+9.16 \mathrm{Co}-36.02 \mathrm{Cu}-41.15 \mathrm{Ru}
\end{gathered}
$$

$B_{\mathrm{S}}\left({ }^{\circ} \mathrm{C}\right)=732-202 \mathrm{C}+216 \mathrm{Si}-85 \mathrm{Mn}-37 \mathrm{Ni}-47 \mathrm{Cr}-39 \mathrm{Mo}$ 


$$
B_{\mathrm{S}}\left({ }^{\circ} \mathrm{C}\right)=711-361.9 \mathrm{C}+261.9 \mathrm{C}^{2}-28.3 \mathrm{Mn}+43.7 \mathrm{Si}
$$

$$
B_{\mathrm{S}}\left({ }^{\circ} \mathrm{C}\right)=630-45 \mathrm{Mn}-40 \mathrm{~V}-35 \mathrm{Si}-30 \mathrm{Cr}-25 \mathrm{Mo}-20 \mathrm{Ni}-15 \mathrm{~W}
$$

$$
\begin{aligned}
B_{\mathrm{S}}\left({ }^{\circ} \mathrm{C}\right)= & 745-110 \mathrm{C}-59 \mathrm{Mn}-39 \mathrm{Ni}-68 \mathrm{Cr}-106 \mathrm{Mo}-17 \mathrm{MnNi} \\
& +6 \mathrm{Cr}^{2}+29 \mathrm{Mo}^{2}
\end{aligned}
$$

$$
\begin{aligned}
B_{\mathrm{S}}\left({ }^{\circ} \mathrm{C}\right)= & 839-270[1-\exp (-1.33 \mathrm{C})]-86 \mathrm{Mn}-23 \mathrm{Si} \\
& -67 \mathrm{Cr}-33 \mathrm{Ni}-75 \mathrm{Mo}
\end{aligned}
$$

It is striking that the numerical values of the coefficients vary considerably between the equations. For Mn it varies from 35 to 90 and for Ni from 15.3 to 66.34. This may partly be caused by the use of different groups of steels by different authors. It may seem that the resulting equation in such a case can give usable predictions for new steels of similar compositions. The equations also differ appreciably when applied to binary $\mathrm{Fe}-\mathrm{C}$ alloys as illustrated in Figure 1. To indicate that they apply to binary $\mathrm{Fe}-\mathrm{C}$ alloys with no alloying elements they will all be denoted as $B_{\mathrm{s}}^{\mathrm{o}}$ lines. It is evident that at least a large majority of the authors have not paid any attention to the consequences for $\mathrm{Fe}-\mathrm{C}$ alloys which may be understandable if their interest was in alloyed steels.

Of course, the evaluated coefficient for an alloying element represents the difference from the properties of the $\mathrm{Fe}-\mathrm{C}$ alloys according to the same equation. It is thus to be expected that the coefficient for an alloying element differs between equations if their predictions for $\mathrm{Fe}-\mathrm{C}$ alloys differ. To obtain an equation that predicts realistic effects of individual alloying elements, it is thus necessary to base the equation on a realistic description of binary $\mathrm{Fe}-\mathrm{C}$ alloys. It may also seem wise to evaluate the coefficient for each alloying element separately because, if two alloying elements occur simultaneously in a large fraction of the alloys, used in the regression analysis, it may be difficult to separate their effects properly. The strategy of the present work was thus to derive an empirical equation by starting with information from binary $\mathrm{Fe}-\mathrm{C}$ alloys and then evaluating the alloying effects one by one from ternary information rather than applying a regression analysis to all the experimental information in one operation. Possible interactions between alloying elements will be neglected. Even among the above equations, which to a large extent have been based on steels with more than one alloying element, only one, Eq. [9], contains a term for interaction between two elements.

An extensive review of $B_{\mathrm{S}}$ information was recently performed by Kolmskog et al. ${ }^{[12]}$ and they paid special attention to binary $\mathrm{Fe}-\mathrm{C}$ alloys for which the direct information was very meagre, possibly due to experimental difficulties, e.g., by rapid formation of cementite and the competition with pearlite. They derived some additional information from the variation of growth rate with the carbon content of alloys. They also included corresponding information on Widmanstätten ferrite, here denoted as $W_{\mathrm{S}}$, accepting the view that there is no difference between bainitic ferrite and Widmanstätten ferrite. ${ }^{[13]}$ In addition to classical $B_{\mathrm{S}}$ information, concerning the critical temperature of bainite formation for fixed composition (method T), Kolmskog et al. also included experimental information on the critical carbon content of bainite formation at fixed temperature and fixed alloy content (method C). They listed the information separately for the experimental $\mathrm{T}$ (temperature) and $\mathrm{C}$ (carbon content) methods but a statistical test did not indicate that they concerned critical conditions for different physical processes. The present work was based on their compilation and results from both methods were accepted.

For Fe-C alloys, or for alloyed steels of some fixed alloy content, the information was expected to form $B_{\mathrm{S}}$ lines. In the present work, $B_{\mathrm{S}}$ lines will be a useful means of illustration and $\mathrm{C}$ method data will be particularly valuable because sets of such data from various temperatures are often presented for some fixed alloy content and they can thus be illustrated directly as a $B_{\mathrm{S}}$ line. Such lines are more seldom obtained from classical $B_{\mathrm{S}}$ information but two examples are presented in Figure 2. One was obtained from a set of $\mathrm{Cr}$ steels with similar alloy content but different carbon contents and another from a set of plain carbon steels.

The straight line was fitted to information from the set of plain carbon steels with an average alloy content of 0.38 petMn and 0.18 pctSi (mass pct). ${ }^{[13]}$ This line was marked $\mathrm{WB}_{\mathrm{S}}$ because it concerned a combination of data from Widmanstätten ferrite from higher temperatures and bainite from lower. As already mentioned, this combination is based on the assumption that there is no difference between acicular ferrite when it forms primarily, whether it will later be found together with cementite, in an arrangement regarded as bainite, or not. Due to a resulting wide temperature range, it could yield some support of the straight extrapolations of lines in Figure 1 outside their experimental ranges.

The filled squares in Figure 2 were obtained by interpreting TTT diagrams from Lyman and Troiano ${ }^{[14]}$ for a set of $\mathrm{Cr}$ steels with an average alloy content of 3.0 $\mathrm{Cr}, 0.26 \mathrm{Mn}$ and $0.20 \mathrm{Si}$ (mass pet). That information indicates a strongly curved $B_{\mathrm{S}}$ line and was recently used by van Bohemen ${ }^{[11]}$ when he derived Eq. [10], which thus predicts a curved $B_{\mathrm{s}}^{\mathrm{o}}$ line for binary $\mathrm{Fe}-\mathrm{C}$ alloys. This may be taken as an illustration that to obtain a reliable empirical equation one should use some information from binary $\mathrm{Fe}-\mathrm{C}$ alloys. Lines for austenite in paraequilibrium, PE, with ferrite are included in Figure 2 for comparison and were calculated for the respective average alloy content using Thermo-Calc software ${ }^{[15]}$ and the TCFE 8 database ${ }^{[16]}$ For the plain carbon steels, there is an increasing distance with lowering temperature between the PE line and experimental information but for the $\mathrm{Cr}$ steels there is a large distance at all 


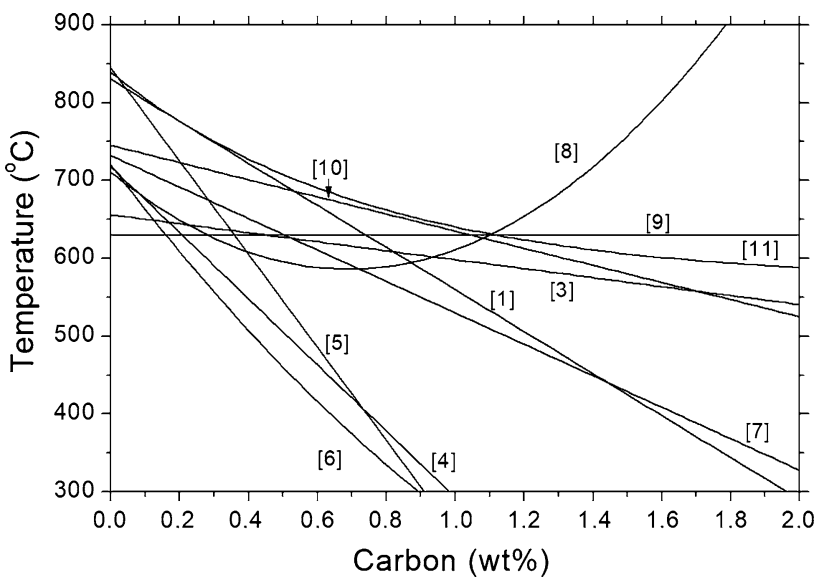

Fig. $1-B_{\mathrm{s}}^{\mathrm{o}}$ lines for $\mathrm{Fe}-\mathrm{C}$ alloys predicted from many empirical equations.

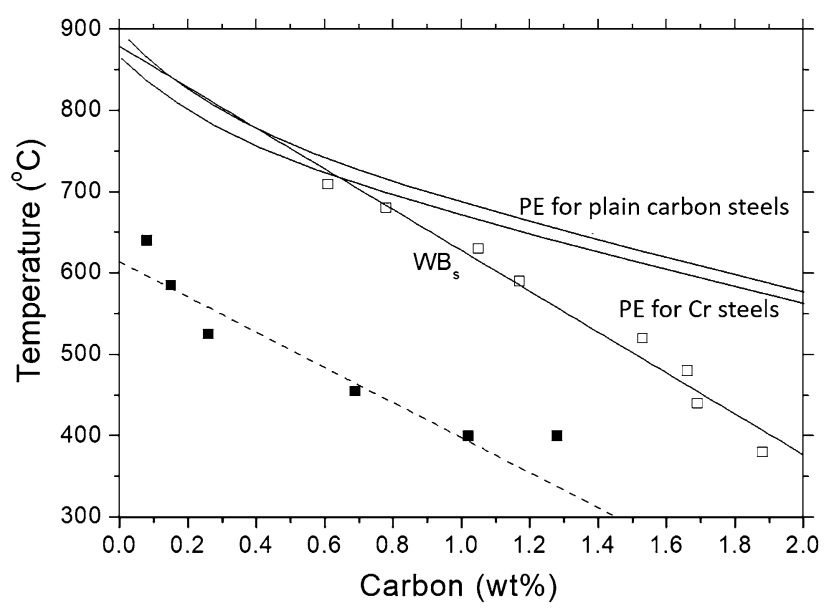

Fig. 2-Filled squares: $B_{\mathrm{S}}$ information from Lyman and Troiano ${ }^{[14]}$ on $\mathrm{Cr}$ steels. Representation by a straight, dashed line shows strong deviation for some points. Open squares: $W_{\mathrm{S}}$ and $B_{\mathrm{S}}$ information from Hillert ${ }^{[13]}$ on plain carbon steels. The straight solid line is the $\mathrm{WB}_{\mathrm{S}}$ line from a least square fit.

temperatures. In principle, it is this effect of alloying elements that will be examined in the following.

\section{ANALYSIS OF EXPERIMENTAL DATA}

\section{A. The $\mathrm{WB}_{s}^{o}$ Line for Binary $\mathrm{Fe}-\mathrm{C}$ Alloys}

The present work was based on the information compiled by Kolmskog et al..$^{[12]}$ It started by focusing on the binary $\mathrm{Fe}-\mathrm{C}$ system for which they had made a special effort. The main results are presented in Figure 3 together with the $B_{\mathrm{S}}^{\mathrm{o}}$ line predicted from Eq. [1] obtained by Steven and Haynes. ${ }^{[1]}$ Six points by Aaronson ${ }^{[17]}$ agree well with the $B_{\mathrm{S}}^{\mathrm{o}}$ line by Steven and Haynes, ${ }^{[1]}$ which had been published a few years earlier. Nevertheless, there is a lack of documentation of his values and they were not considered when a linear regression analysis was done. It was performed using only the filled symbols in Figure 3 which originate from Johanson, ${ }^{[18]}$

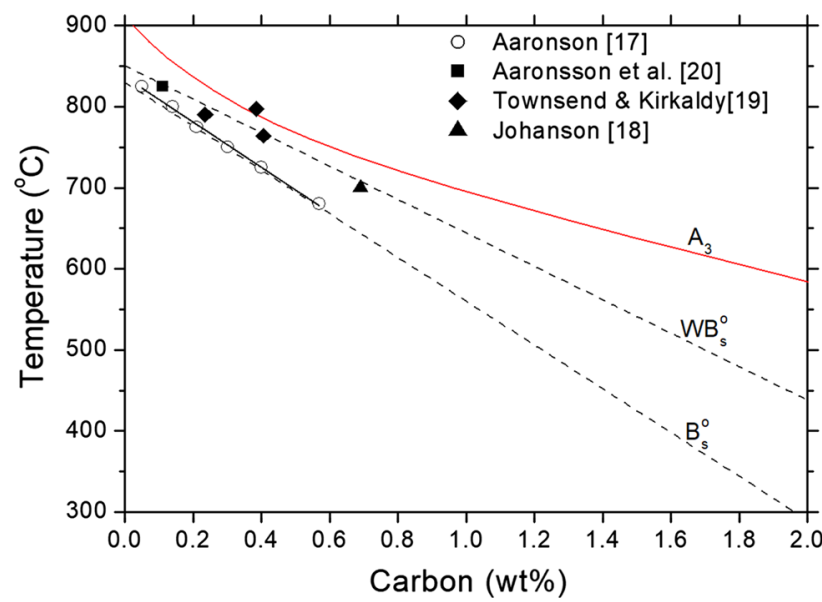

Fig. 3-Experimental information from Fe-C alloys. The dashed $B_{\mathrm{S}}^{\mathrm{o}}$ line is extrapolated to $\mathrm{Fe}-\mathrm{C}$ alloys using Eq. [1] by Steven and Haynes. ${ }^{[1]}$ The dashed $\mathrm{WB}_{\mathrm{s}}^{\mathrm{o}}$ line is the result of the present linear regression analysis of all the filled symbols.

Townsend and Kirkaldy ${ }^{[19]}$ and Aaronson et al. ${ }^{[20]}$ It gave the following result and the corresponding line is included in Figure 3 as a line denoted as $\mathrm{WB}_{\mathrm{s}}^{\mathrm{o}}$ to emphasize that it concerns Widmanstätten ferrite as well as bainite in binary Fe-C alloys.

$$
W B_{\mathrm{s}}^{\mathrm{o}}\left({ }^{\circ} \mathrm{C}\right)=850-206 \mathrm{C}
$$

The $W_{\mathrm{s}}^{\mathrm{o}}$ line in Figure 3 has been extended far outside the experimental range. The extension could possibly be tested using the information from plain carbon steels, presented in Figure 2, by neglecting the effects of their $\mathrm{Mn}$ and $\mathrm{Si}$ contents. That information covers a much wider range of carbon content. That test will be made later in connection to the assessment of the effect of Mn.

For binary Fe-C alloys, the PE line degenerates to the $\mathrm{A}_{3}$ line, which is included in Figure 3, and the growing distance from the $\mathrm{WB}_{\mathrm{s}}^{\mathrm{o}}$ line with increasing carbon content demonstrates that the conditions at the interface of the growing acicular ferrite may be rather close to equilibrium at low carbon contents but may deviate markedly at higher carbon contents. According to the strategy of the present work, the $\mathrm{WB}_{\mathrm{s}}^{\mathrm{o}}$ line will now be accepted as the $\mathrm{Fe}-\mathrm{C}$ reference in the assessments of the effects of alloying elements from ternary information.

\section{B. Analysis of Information from Ternary Systems}

The two coefficients for Fe-C alloys in Eq. [11] will now be applied to ternary $\mathrm{Fe}-\mathrm{C}-\mathrm{X}$ systems and the effects of alloying elements will be evaluated for each system. Interactions between elements will be neglected and the resulting equations will thus be linear. As a consequence, it should not be necessary to use information from quaternary alloys but such information will be used when the information from a ternary system is not self-consistent.

Most $B_{\mathrm{S}}$ information is available from separate alloys and effects of alloying elements can then be derived by 
linear regression analysis. However, for ternary systems there is sometimes information from a set of alloys with the same alloying element content but varying carbon content. As mentioned in the introduction, the $B_{\mathrm{S}}$ values from such sets should in principle be combined into $\mathrm{WB}_{\mathrm{S}}$ lines but experimental scatter may result in a cloud of points around an imagined ideal line. It is then possible to estimate experimental scatter directly. Furthermore, according to a linear approach, the slope of the $\mathrm{WB}_{\mathrm{S}}$ line for a fixed alloy content in a $T, C$ diagram is given by the second term in the empirical equation and such $\mathrm{WB}_{\mathrm{S}}$ lines for all alloying elements should be straight and parallel to the $\mathrm{WB}_{\mathrm{s}}^{\mathrm{o}}$ line for binary $\mathrm{Fe}-\mathrm{C}$ alloys. Due to non-linearity in the experimental information, there may be deviations from this rule but they should at least vary in a systematic way. This is thus a second way to check the quality of information. It was decided to rely on such sets of $B_{\mathrm{S}}$ values when available.

1. $\mathrm{Fe}-\mathrm{C}-\mathrm{Mn}$

Liu et al. ${ }^{[21,22]}$ studied the critical carbon content in a ternary alloy with 2.99 mass pet $\mathrm{Mn}$ at a series of temperatures and results are plotted in Figure 4 together with the PE line and the $B_{\mathrm{S}}^{\mathrm{o}}$ and $\mathrm{WB}_{\mathrm{s}}^{\mathrm{o}}$ lines for $\mathrm{Fe}-\mathrm{C}$ alloys from Figure 3. The points fall onto a straight, imagined $\mathrm{WB}_{\mathrm{S}}$ line, roughly parallel to the $B_{\mathrm{S}}^{\mathrm{o}}$ or $\mathrm{WB}_{\mathrm{S}}^{\mathrm{o}}$ line. Direct estimate of the vertical distance of that line from the $\mathrm{WB}_{\mathrm{s}}^{\mathrm{O}}$ line yields a Mn coefficient of about -80 $\mathrm{K} /$ pct, which may be compared with values from - 91.68 to -35 in Eqs. [1] through [10].

For regression analysis, information was added from Borgenstam $^{[23]}$ who studied a number of Mn contents but only three temperatures for each alloy. In addition, five single $B_{\mathrm{S}}$ values on ternary $\mathrm{Fe}-\mathrm{C}-\mathrm{Mn}$ alloys ${ }^{[20-26]}$ were accepted. As already explained, information on plain carbon steels in Figure 2 was included and also the five black points in Figure 3 that yielded the $\mathrm{WB}_{\mathrm{s}}^{\mathrm{o}}$ line. All this information is collected in Figure 5 where values from sets of the same alloy content were connected by short straight lines to show their relation. It is interesting that all of the lines for alloys from Borgenstam have

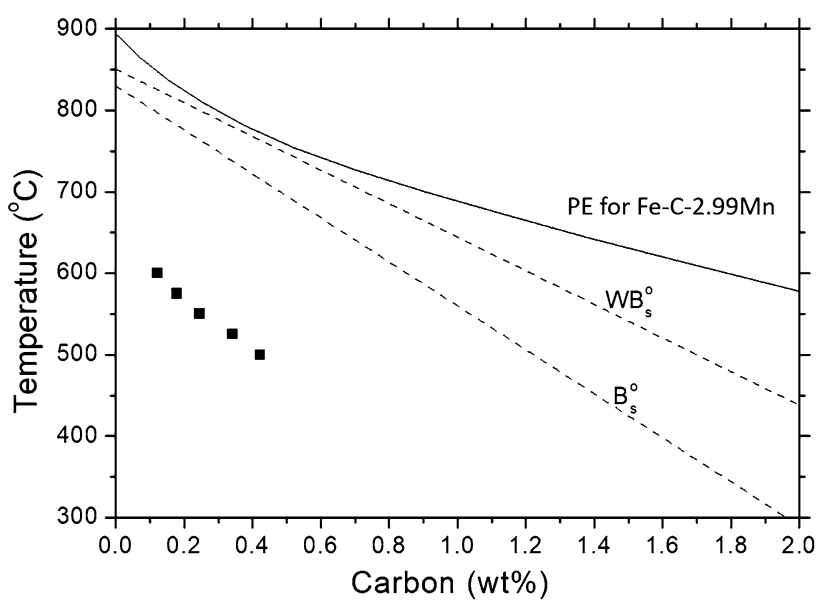

Fig. $4-B_{\mathrm{S}}$ values from Liu et al. ${ }^{[22]}$ from ternary Fe-C-2.99 Mn alloys with different carbon contents. They are compared with the dashed $B_{\mathrm{S}}^{\mathrm{o}}$ and $\mathrm{WB}_{\mathrm{s}}^{\mathrm{o}}$ lines from Fig. 3. negative slopes as the line for the alloy from Liu et al. but the scatter is appreciable.

A linear regression analysis was done with all information in Figure 5. The following equation was thus obtained,

$$
\mathrm{WB}_{\mathrm{S}}\left({ }^{\circ} \mathrm{C}\right)=854-212 \mathrm{C}-79 \mathrm{Mn}
$$

This result is illustrated in Figure 6 with $\mathrm{WB}_{\mathrm{S}}$ lines calculated for the experimental Mn contents of the sets of alloys with equal alloy contents. The first two coefficients in Eq. [12] agree well with those in Eq. [11], which is demonstrated by the similarity between the $0 \mathrm{Mn}$ and $\mathrm{WB}_{\mathrm{s}}^{\mathrm{o}}$ lines. One may thus consider the information from plain carbon steels, which was added to Figure 5, as support for Eq. [11]. The Mn coefficient agrees excellently with the value of $-80 \mathrm{~K} /$ pct, evaluated directly from the same information when given in Figure 4. It would thus seem attractive to accept all the coefficients as given by Eq. [12]. However, in line with the strategy to start with the binary information, it was instead decided to accept Eq. [11] and evaluate only the Mn coefficient from the regression analysis. It yielded Eq. [13] which gave only a marginal change of the Mn coefficient.

$$
\mathrm{WB}_{\mathrm{s}}^{\mathrm{o}}\left({ }^{\circ} \mathrm{C}\right)=850-206 \mathrm{C}-78 \mathrm{Mn}
$$

\section{2. $\mathrm{Fe}-\mathrm{C}-\mathrm{Ni}$}

There is much information from ternary Fe-C-Ni alloys ${ }^{[18,20,27-30]}$ but few sets with constant alloy content. The information is presented in Figure 7 where the three circles for 1 mass pet $\mathrm{Ni}$ from Johanson, ${ }^{[18]}$ combined with the single cross for 1.06 mass pct $\mathrm{Ni}$ from Aaronson et al., ${ }^{[20]}$ can give a reasonably straight $\mathrm{WB}_{\mathrm{S}}$ line parallel to the $\mathrm{WB}_{\mathrm{s}}^{\mathrm{o}}$ line. Imagined slopes for the other alloy contents show the same tendency but with

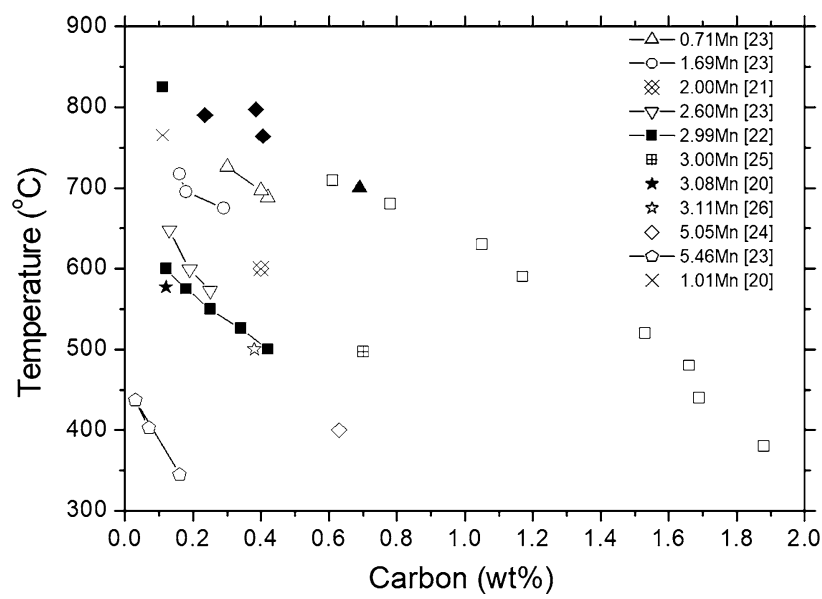

Fig. 5- $B_{\mathrm{S}}$ values from Fig. 4 combined with information from other sets of $\mathrm{Fe}-\mathrm{C}-\mathrm{Mn}$ alloys with constant alloy contents. Comparison is also made with plain carbon steels with the information in Fig. 2 and Fe-C alloys with the information in Fig. 3 but the data by Aaronson ${ }^{[17]}$ were excluded. 


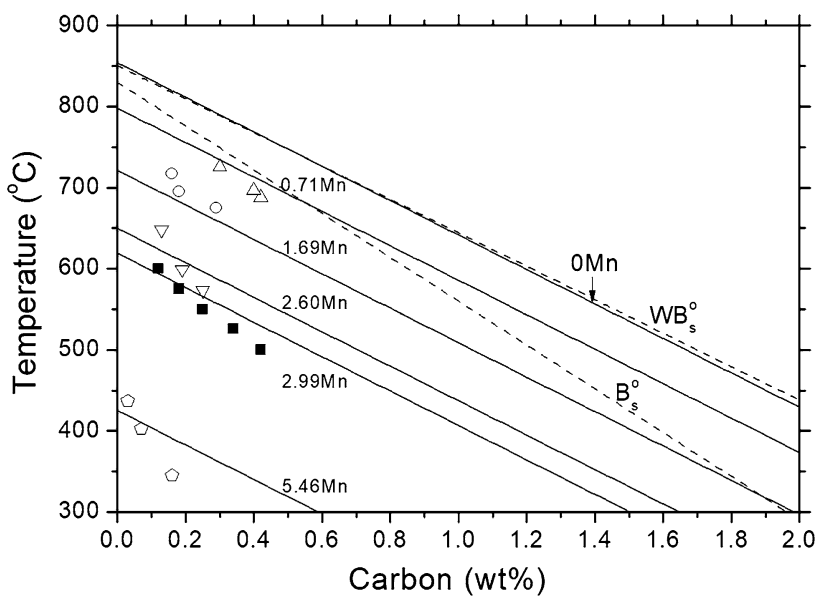

Fig. 6-Linear regression analysis of all information in Fig. 5. Results are presented as $\mathrm{WB}_{\mathrm{S}}$ lines for the $\mathrm{Mn}$ contents of the experimental information. The result for zero $\mathrm{Mn}$ content should ideally be identical to the $\mathrm{WB}_{\mathrm{s}}^{\mathrm{o}}$ line from Fig. 3 for $\mathrm{Fe}-\mathrm{C}$ alloys. Information on experimental points is given in Fig. 5.

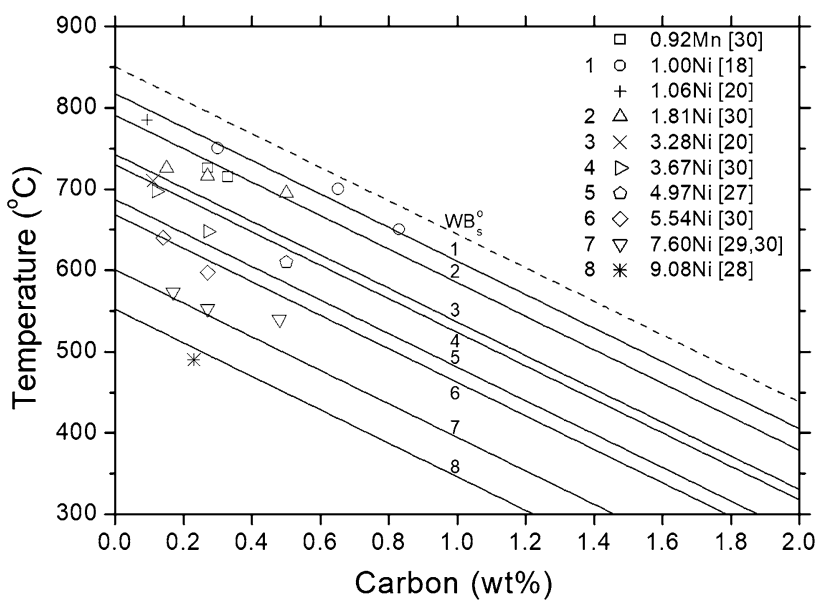

Fig. 7- $B_{\mathrm{S}}$ information from $\mathrm{Fe}-\mathrm{C}-\mathrm{Ni}$ alloys. Symbols for each alloy content should ideally form a $\mathrm{WB}_{\mathrm{S}}$ line. That is most evident by combining information on 1.00 and 1.06 mass pet $\mathrm{Ni}$ which gives a $\mathrm{WB}_{\mathrm{S}}$ line parallel to the $\mathrm{WB}_{\mathrm{s}}^{\mathrm{o}}$ line for $\mathrm{Fe}-\mathrm{C}$ alloys.

less distinction. A linear regression analysis with the two coefficients from Eq. [11] fixed gave

$$
\mathrm{WB}_{\mathrm{S}}\left({ }^{\circ} \mathrm{C}\right)=850-206 \mathrm{C}-33 \mathrm{Ni}
$$

The family of parallel $\mathrm{WB}_{\mathrm{S}}$ lines in Figure 7 were calculated from Eq. [13] for the experimental $\mathrm{Ni}$ contents. There is a reasonable fit in the whole range of $\mathrm{Ni}$ contents but only the information from 1.00 mass pct Ni cover a sufficiently wide range of carbon contents to directly support the evaluated slope of the parallel $\mathrm{WB}_{\mathrm{S}}$ lines.

\section{3. $\mathrm{Fe}-\mathrm{C}-\mathrm{Cr}$}

$B_{\mathrm{S}}$ information from $\mathrm{Fe}-\mathrm{C}-\mathrm{Cr}$ alloys is presented in Figure 8 and there are several sources ${ }^{[20,23,27,31-33]}$ and most of them with sets of alloys with the same alloy content but different carbon contents. Straight,

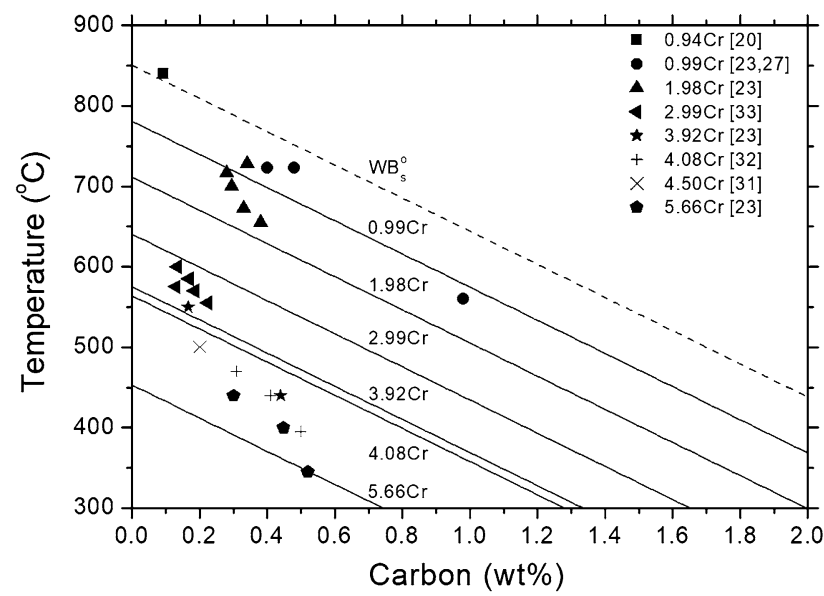

Fig. 8- $B_{\mathrm{S}}$ information from $\mathrm{Fe}-\mathrm{C}-\mathrm{Cr}$ alloys. Data of each kind of symbol should ideally form a $B_{\mathrm{S}}$ line. They often seem to be steeper than the $\mathrm{WB}_{\mathrm{s}}^{\mathrm{o}}$ line for $\mathrm{Fe}-\mathrm{C}$ alloys.

imagined $\mathrm{WB}_{\mathrm{S}}$ lines for these sets would give negative slopes with a tendency to be steeper than the $\mathrm{WB}_{\mathrm{s}}^{\mathrm{o}}$ line derived for binary $\mathrm{Fe}-\mathrm{C}$ alloys. A linear regression analysis of all the information in this figure was done but with the two first coefficients fixed to the values in Equation 11. The result was

$$
\mathrm{WB}_{\mathrm{S}}\left({ }^{\circ} \mathrm{C}\right)=850-206 \mathrm{C}-70 \mathrm{Cr}
$$

The family of parallel $\mathrm{WB}_{\mathrm{S}}$ lines in Figure 8 were calculated from Eq. [15] for the experimental $\mathrm{Cr}$ contents and seem to represent the information reasonably well, considering the experimental scatter, which is directly noticed for sets of equal alloy content. However, there are obvious cases of deviation.

\section{4. $\mathrm{Fe}-\mathrm{C}-\mathrm{Mo}$}

$B_{\mathrm{S}}$ information from $\mathrm{Fe}-\mathrm{C}-\mathrm{Mo}$ alloys is presented in Figure 9 and there are many sources ${ }^{[20,34-40]}$ and several of them with sets of alloys with the same alloy content but different carbon contents. Straight, imagined $\mathrm{WB}_{\mathrm{S}}$ lines for these sets would have slopes that agree better with the $\mathrm{WB}_{\mathrm{s}}^{\mathrm{o}}$ line than the imagined $\mathrm{WB}_{\mathrm{S}}$ lines for $\mathrm{Fe}$ $\mathrm{C}-\mathrm{Cr}$ alloys would do. Examples are the standing triangles and the asterisks. A linear regression analysis with the two coefficients from Eq. [11] fixed gave

$$
\mathrm{WB}_{\mathrm{S}}\left({ }^{\circ} \mathrm{C}\right)=850-206 \mathrm{C}-75 \mathrm{Mo}
$$

The family of parallel $\mathrm{WB}_{\mathrm{S}}$ lines in Figure 9 were calculated from Eq. [16] for the experimental Mo contents. There is reasonable agreement around 2.5 mass pet Mo but alloys with lower Mo contents fall below their $\mathrm{WB}_{\mathrm{S}}$ lines.

\section{5. $\mathrm{Fe}-\mathrm{C}-\mathrm{Si}$}

For ternary Fe-C-Si alloys, there are two sets of $B_{\mathrm{S}}$ values for constant $\mathrm{Si}$ content by Pevzner et al ${ }^{[41]}$ and Papadimitriou et al. ${ }^{[42]}$ with 2.69 and 3.85 mass pet Si, respectively. The values are plotted in Figure 10 together with $B_{\mathrm{S}}^{\mathrm{o}}, \mathrm{WB}_{\mathrm{s}}^{\mathrm{o}}$ and $\mathrm{A}_{3}$ lines for $\mathrm{Fe}-\mathrm{C}$ alloys 


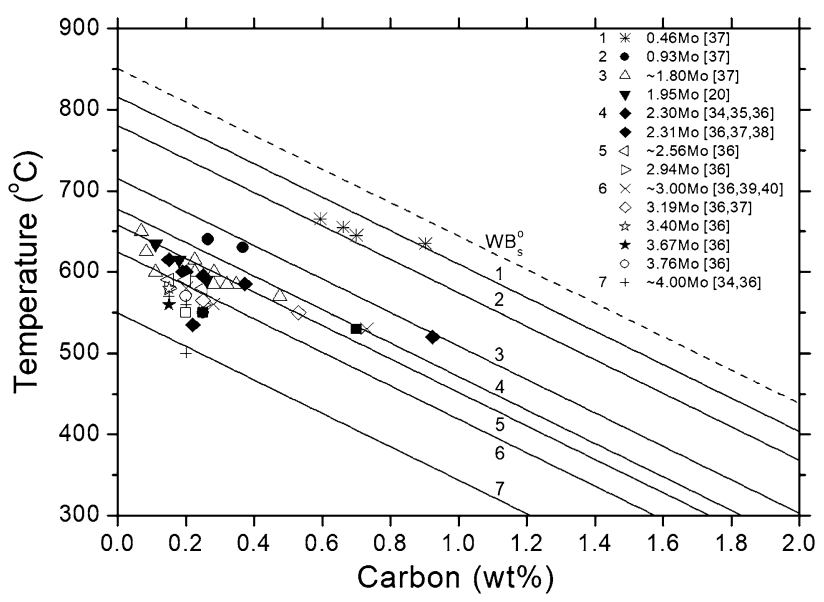

Fig. $9-B_{\mathrm{S}}$ information from Fe-C-Mo alloys. Each kind of symbol should ideally form a $\mathrm{WB}_{\mathrm{S}}$ line.

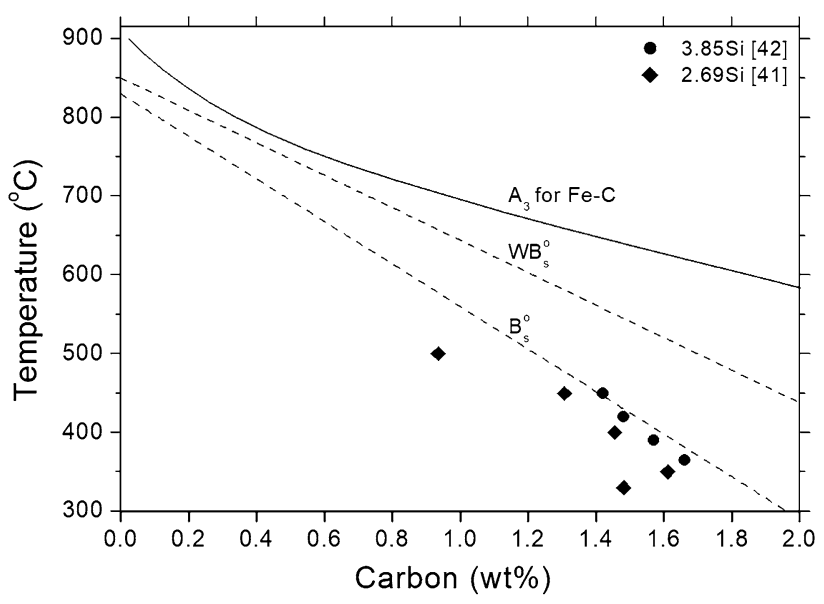

Fig. $10-B_{\mathrm{S}}$ information on Fe-C-Si alloys from two sets of constant alloy content. Pevzner et al. ${ }^{[41]}$ used $2.69 \mathrm{Si}$ and Papadimitriou et al. ${ }^{[42]}$ used $3.85 \mathrm{Si}$.

from Figure 3 for comparison. Even though the experimental range of carbon content is limited, the four circles from Papadimitriou et al. could define a straight, imagined $\mathrm{WB}_{\mathrm{S}}$ line very well and it would be only slightly steeper than the $\mathrm{WB}_{\mathrm{s}}^{\mathrm{o}}$ line for Fe-C alloys. The lowest diamond from Pevzner et al. will be neglected because the rejection of carbon from the precipitated ferrite may not be complete due to insufficient annealing time, considering how low that temperature is. The next three diamonds would define a straight, imagined $\mathrm{WB}_{\mathrm{S}}$ line with a slope supporting the slope of the first set. However, the two sets are in conflict because they refer to different $\mathrm{Si}$ contents and the one with the lower $\mathrm{Si}$ content is further away from the $\mathrm{WB}_{\mathrm{s}}^{\mathrm{o}}$ line than the other. The coefficient for $\mathrm{Si}$ was evaluated for both from their vertical distance from the $\mathrm{WB}_{\mathrm{s}}^{\mathrm{o}}$ line, yielding -56 and $-32 \mathrm{~K} /$ pct, respectively. This could indicate that one of the sets has a strong systematic error or both have. The effect of $\mathrm{Si}$ cannot be estimated without further information, which might be obtained from quaternary alloys.

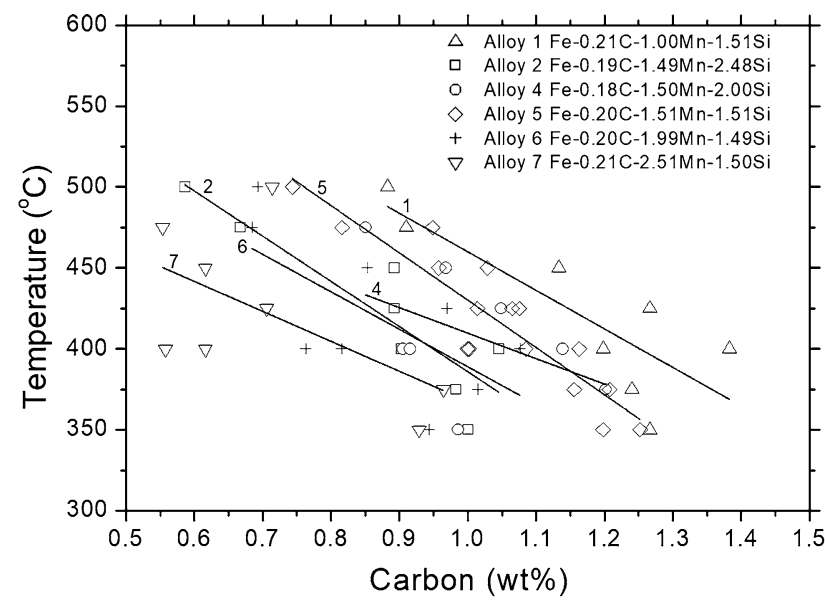

Fig. 11-Combination of $B_{\mathrm{S}}$ values from Fe-C-Mn-Si alloys from Usui et al. ${ }^{[43]}$ and Sugimoto et al. ${ }^{[4,45]}$ There are six alloy contents, each with several carbon contents. Straight lines are least square representations for equal alloy content.

\section{Evaluating the Effect of Si from Quaternary Information}

Valuable information for evaluating the coefficient for $\mathrm{Si}$ may be obtained from Fe-C-Mn-Si alloys since the effect of Mn has now been established. Usui et al. ${ }^{[43]}$ and Sugimoto et al. ${ }^{[4,45]}$ have performed a very thorough study of the critical carbon content for bainite formation for seven alloy contents and over a wide range of temperatures. All the $B_{\mathrm{S}}$ values are presented in Figure 11 and, in principle, each set for a fixed alloy content should form a $\mathrm{WB}_{\mathrm{S}}$ line. A least square fit was done on each set to estimate the slope of its $\mathrm{WB}_{\mathrm{S}}$ line. The resulting straight lines for six of the alloy contents are included in Figure 11. The information from the third set was excluded because it covered a narrow range of carbon contents and the line was not well defined.

The six lines are not very parallel but point in the same general direction as the $\mathrm{WB}_{\mathrm{s}}^{\mathrm{o}}$ line in Figure 3. A linear regression analysis was done without fixing any coefficient, which was possible because the information now included different contents of both $\mathrm{Mn}$ and $\mathrm{Si}$. The following equation was obtained,

$$
\mathrm{WB}_{\mathrm{S}}\left({ }^{\circ} \mathrm{C}\right)=833-241 \mathrm{C}-74 \mathrm{Mn}-36 \mathrm{Si}
$$

The first two coefficients in Eq. [17] represent Fe-C alloys and it is thus surprising but promising that they agree rather well with Eq. [11]. It may seem tempting to accept all coefficients in Eq. [17] but the present strategy was to rely on binary and ternary information as far as possible. The present linear regression analysis was thus repeated with the $\mathrm{C}$ and $\mathrm{Mn}$ coefficients fixed to the values in Eq. [13]. Only the coefficient for Si was thus evaluated here and the following equation was obtained,

$$
\mathrm{WB}_{\mathrm{S}}\left({ }^{\circ} \mathrm{C}\right)=850-206 \mathrm{C}-78 \mathrm{Mn}-61 \mathrm{Si}
$$

It is interesting that the $\mathrm{Si}$ coefficient was almost doubled compared to Eq. [17] although they are both based on the same $\mathrm{Si}$ information. The difference is 
explained by the difference in the first two coefficients that represent $\mathrm{Fe}-\mathrm{C}$ alloys. This exemplifies the fact that an error in one coefficient can be partly compensated by accepting an error in another coefficient. Here, it demonstrates the importance of starting an evaluation of coefficients from $\mathrm{Fe}-\mathrm{C}$ alloys and then continuing to ternary alloys, without revising the two Fe-C coefficients later on. For the same reason, it would not have been wise to accept the $\mathrm{Mn}$ value of $-74 \mathrm{~K} /$ pct in Eq. [17] from quaternary alloys, obtained together with a $\mathrm{Si}$ value. That is why not only the two $\mathrm{Fe}-\mathrm{C}$ coefficients from Eq. [13] were fixed in the last regression analysis, but also the $\mathrm{Mn}$ value of $-78 \mathrm{~K} /$ pct.

It is now a question whether $-61 \mathrm{~K} /$ pct should be accepted as the coefficient for Si. Comparison with the values from the ten empirical expressions, listed as Eqs. [1] through [10], gave no valuable indication because their values spread from -75 to $+216 \mathrm{~K} / \mathrm{pct}$ for $\mathrm{Si}$, which is connected to the large differences between the coefficients for the other elements. Comparison with the information from ternary $\mathrm{Fe}-\mathrm{C}-\mathrm{Si}$ alloys in Figure 10, which yielded two alternatives for the $\mathrm{Si}$ coefficient, -32 or $-56 \mathrm{~K} / \mathrm{pct}$, showed a promising similarity to the second value. It was reported by Pevzner et al. ${ }^{[41]}$ and it may be concluded that the first value, which was reported by Papadimitriou et $a l .{ }^{[42]}$ and showed only small scatter, had a strong systematic error. In line with the strategy of the present work, it may seem that one should accept $-56 \mathrm{~K} /$ pct because it was obtained from a ternary alloy, rather than - $61 \mathrm{~K} /$ pct based on quaternary information. However, instead of relying on the single ternary study by Pevzner et al., which showed strong scatter, it was decided to accept $-61 \mathrm{~K} /$ pct from Eq. [18]. On the other hand, the difference between -56 and -61 is small and the choice between them may not be critical. A family of $\mathrm{WB}_{\mathrm{S}}$ lines for the six alloy contents were finally calculated from Eq. [18] with the Si coefficient of - 61 $\mathrm{K} /$ pct and were plotted in Figure 12. They show reasonable agreement with the experimental information but also demonstrate the experimental scatter.

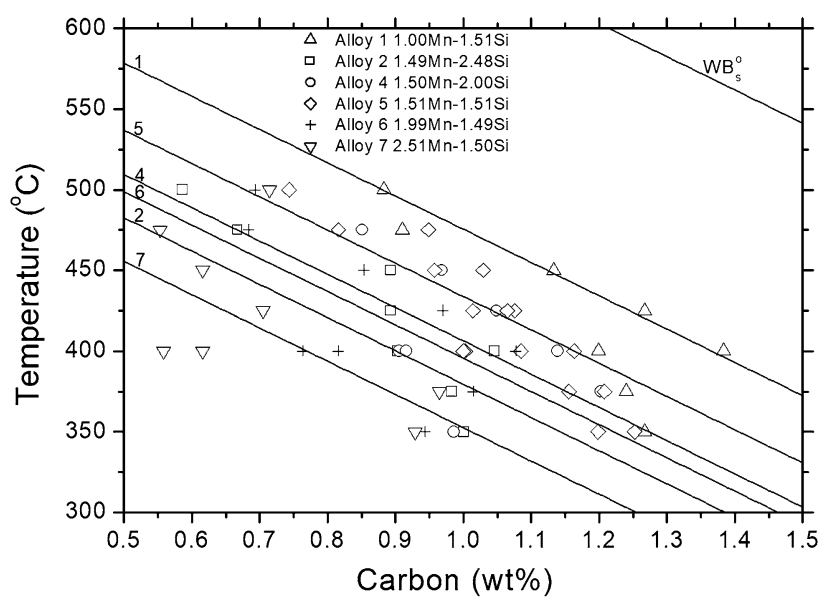

Fig. 12-Result of linear regression analysis of Fe-C-Mn-Si data in Fig. 11 to evaluate the coefficient for Si.

\section{DISCUSSION}

\section{A. Consequences of Linear Equation}

The present work is concerned with the rationalization of available experimental information on the critical condition of bainite formation, usually represented by $B_{\mathrm{S}}$ temperatures. That information has many times been described with linear equations and the coefficients have been derived directly by optimized fitting to a large amount of experimental $B_{\mathrm{S}}$ information and without any interpretation or input from physical understanding or modeling. They may thus be regarded as empirical equations and most of Eqs. [1] through [10] are examples. This was also accepted in the present work and the following empirical equation was obtained by combining the various coefficients obtained in Section IV.

$$
W B_{\mathrm{S}}\left({ }^{\circ} \mathrm{C}\right)=850-206 \mathrm{C}-78 \mathrm{Mn}-33 \mathrm{Ni}-70 \mathrm{Cr}-75 \mathrm{Mo}-61 \mathrm{Si}
$$

The aim of the present work was to evaluate the first two coefficients from information on binary $\mathrm{Fe}-\mathrm{C}$ alloys. Historically, bainite was understood as an acicular microstructure of ferrite and cementite and could thus be regarded as a eutectoid microstructure but different from pearlite, which is a eutectoid with cells of ideally spherical shape. As a eutectoid microstructure, bainite should contain some fraction of cementite and could not be expected to form in alloys without carbon. Nevertheless, all empirical equations, including Eq. [19], predict $B_{\mathrm{S}}$ temperatures for zero carbon. Due to the linear kind of equation, $B_{\mathrm{S}}$ lines have been forced to start from zero carbon content and to be straight and parallel, independent of the alloy content. It is an important question whether available experimental information supports the use of a linear equation. That will be further discussed but there will be no effort to support a starting point from information on carbonfree iron. The first term in Eq. [19] was simply obtained by linear extrapolation from $\mathrm{Fe}-\mathrm{C}$ alloys. For previous empirical equations, the first two coefficients were obtained by linear extrapolations for alloyed steels and the numerical values depended on the selected group of steels.

Figure 2 displayed an example which seemed to indicate that a $B_{\mathrm{S}}$ line can be far from straight which would imply that the linear equation is not adequate to represent the properties of the $B_{\mathrm{S}}$ function. In that case, there may not be any reason to extend the $B_{\mathrm{S}}$ line back to pure iron. However, a $B_{\mathrm{S}}$ line was now calculated from the new Eq. [19] for the average composition of the $\mathrm{Cr}$ steels and that is the dashed line which was already plotted in Figure 2. It appears to be a reasonable representation of three of the experimental data and it is suggested that the impression of a curved $\mathrm{WB}_{\mathrm{S}}$ line is caused by major errors in two of the experimental points. It should be mentioned that these data were read from published TTT diagrams which cannot be expected to give very reliable results. It seems reasonable not to 
accept a curved $B_{\mathrm{S}}$ line connecting the points for the $\mathrm{Cr}$ steels in Figure 2.

\section{B. Combination of $B_{S}$ and $W_{S}$ Temperatures}

The examination of published empirical equations for $B_{\mathrm{S}}$ temperatures revealed that they make very different predictions of $B_{\mathrm{S}}$ temperatures for the $\mathrm{Fe}-\mathrm{C}$ alloys and the coefficient for an alloying element would not have the same value in different equations even if they had been fitted to the same $B_{\mathrm{S}}$ temperature. The problem was caused by the lack of $B_{\mathrm{S}}$ information on binary Fe$\mathrm{C}$ alloys because there is an important range of temperature and carbon content where acicular ferrite has been classified as Widmanstätten ferrite. As already mentioned, the coefficients for carbon had thus been obtained by extrapolation from $B_{\mathrm{S}}$ information on alloyed steels. The aim of the present work was to derive an equation that could make reasonable predictions of $B_{\mathrm{S}}$ temperatures in $\mathrm{Fe}-\mathrm{C}$ alloys. The coefficients for alloying elements could only then have proper physical meaning. This would be possible if one could accept information on the critical temperature of Widmanstätten ferrite, $W_{\mathrm{S}}$, as if it concerns bainite. For a very long time, there has been an on-going debate regarding the basic relation between bainite and acicular ferrite but it will not be discussed in the present attempt to derive an empirical equation because it was done without any physical modeling. The use of $W_{\mathrm{S}}$ information will instead be justified by well-known microscopic observations. Bainite was originally regarded as an acicular eutectoid mixture of ferrite and cementite although ferrite was observed to be the leading phase. Usually, cementite appears almost simultaneously to acicular ferrite in lower bainite. However, primary plates or laths of ferrite have more time to develop in upper bainite and it will then be more evident that ferrite is the leading phase. In a transition range of temperature, it is just a matter of taste whether to define acicular ferrite, observed in the microscope, as the ferritic constituent of bainite or Widmanstätten ferrite and to denote the critical temperature of formation as $B_{\mathrm{S}}$ or $W_{\mathrm{S}}$. In the latter case one has reported the results as $W_{\mathrm{S}}$ temperatures. Si as an alloying element in steel will delay the formation of cementite and allow primary ferrite to grow larger before cementite appears and the transition range will move to lower temperatures. For low temperatures, it is now fairly common to regard primary plates or laths of ferrite as bainite even when cementite is very much delayed or not even observed. The $B_{\mathrm{S}}$ temperature is then defined as the critical temperature of the formation of acicular ferrite, whether it appears together with cementite or not. This is a common procedure at low temperatures and in the present work it was extended to higher temperatures where some $W_{\mathrm{S}}$ temperatures have been reported for $\mathrm{Fe}-\mathrm{C}$ alloys.

The information from plain carbon steels, which was displayed in Figure 2, contains both $B_{\mathrm{S}}$ and $W_{\mathrm{S}}$ information and is represented by a fairly straight line. In Figure 5, it is displayed together with more $W_{\mathrm{S}}$ information and it is seen that all of that could be reasonably represented by a straight line. This seems to support that the combination of them to yield an empirical equation for prediction of critical values.

\section{Test of New Equation}

The new Eq. [19] was now tested by application to all the alloys with relevant experimental information compiled by Kolmskog et al. ${ }^{[12]}$ The results are presented in Figure 13 for $\mathrm{T}$ method data and in Figure 14 for $\mathrm{C}$ method data. The RMS of the deviations was $70 \mathrm{~K}$ and $76 \mathrm{~K}$, respectively. When Kolmskog et al. ${ }^{[12]}$ tested the Steven and Haynes equation to the same data they obtained similar results, $72 \mathrm{~K}$ and $87 \mathrm{~K}$, respectively. It seems that the new equation is only slightly better than the classical one in applications to alloyed steels in general. On the other hand, it is most probably superior for estimating the effects of individual alloying elements.

Available empirical equations for predicting $B_{\mathrm{S}}$ temperatures of steels are mainly based on information from some selection of commercial steels. Their predictions for Fe-C alloys reveal a considerable scatter, which is not surprising because the analytical descriptions of the binary $\mathrm{Fe}-\mathrm{C}$ alloys are obtained by extrapolation from alloyed steels. Evidently, the differences in results depend on differences between the selected steels. The considerable scatter is very serious because the evaluated effects of alloying elements are given relative to the particular $\mathrm{Fe}-\mathrm{C}$ description in each equation. To study alloying effects, it is thus necessary to have access to reliable information on $\mathrm{Fe}-\mathrm{C}$ alloys and an equation for predicting $B_{\mathrm{S}}$ temperatures must contain a realistic description of binary $\mathrm{Fe}-\mathrm{C}$ alloys which is presented in this paper.

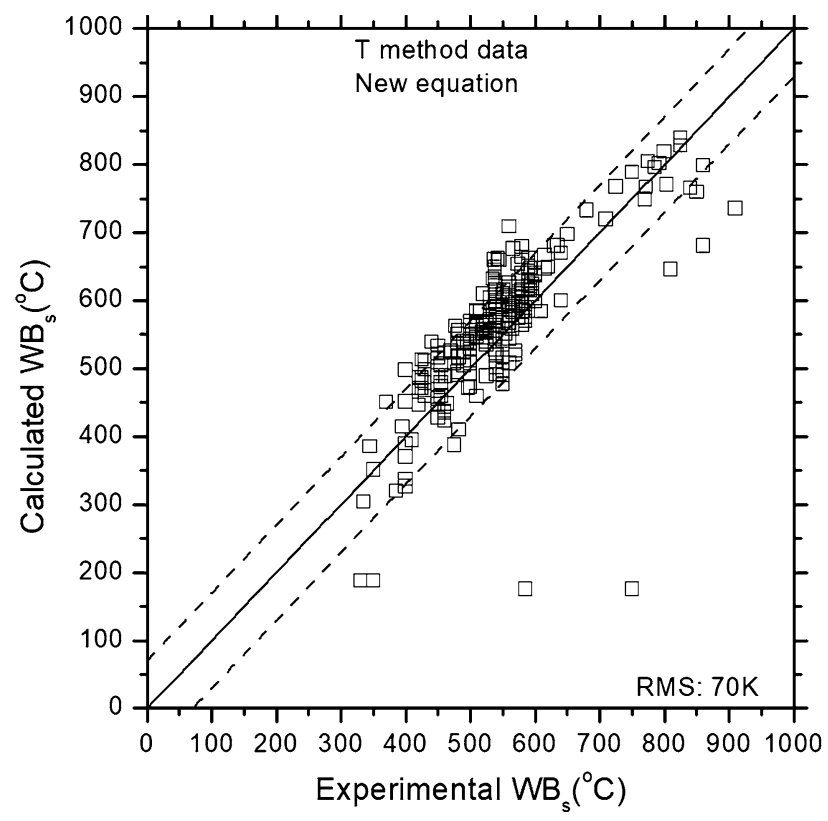

Fig. 13 - Comparison of experimental $W_{\mathrm{S}}$ and $B_{\mathrm{S}}$ values from $T$ methods and predicted values from new equation. 


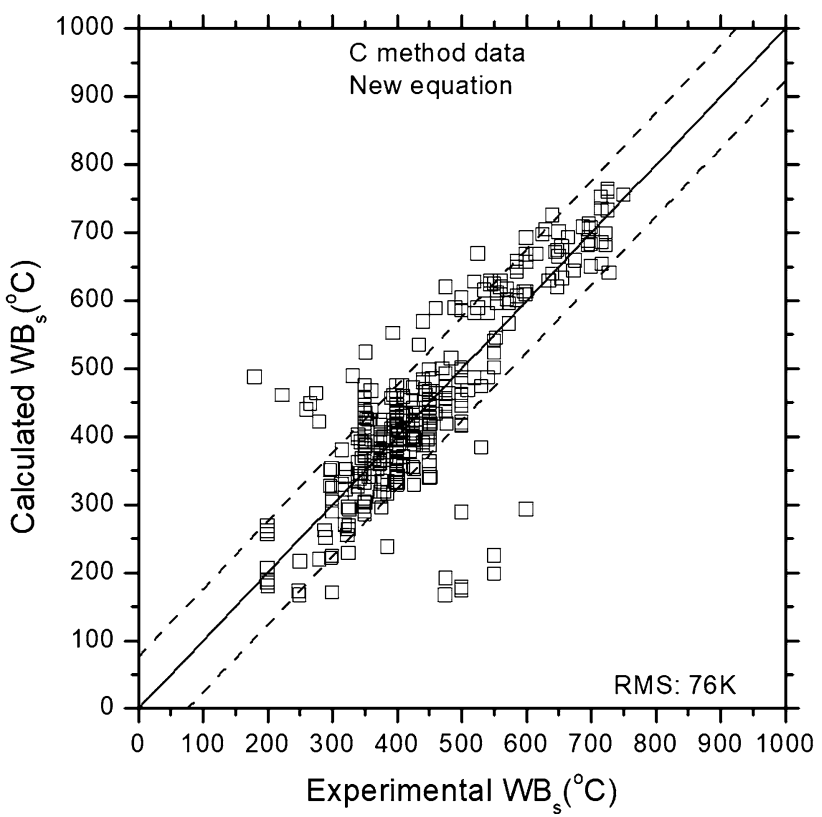

Fig. 14 Comparison of experimental $W_{\mathrm{S}}$ and $B_{\mathrm{S}}$ values from $C$ methods and predicted values from new equation.

\section{SUMMARY}

The effect of an alloying element on the $B_{\mathrm{S}}$ temperature can be expressed only relative to the behavior of binary Fe-C alloys. Such information is not easily available and it is generally accepted to study the alloying effect simultaneously for several elements by some kind of regression analysis of information from a considerable number of steels. An equation of the $B_{\mathrm{S}}$ temperature for $\mathrm{Fe}-\mathrm{C}$ alloys is then obtained together with the effects of alloying elements relative to that equation. However, there have been several such efforts and a comparison of the predicted behavior of binary $\mathrm{Fe}-\mathrm{C}$ alloys show wide scatter. As a consequence, the effects of individual alloying elements also show wide scatter. On the other hand, the result of such an effort may still be of some practical value if it was based on information from a limited range of alloyed steels and only applied to the same kind of steels. However, it would be difficult to analyze the physical factors behind the effects of individual elements.

The primary aim of the present work was to find an equation of the $B_{\mathrm{S}}$ temperature as function of the carbon content in binary $\mathrm{Fe}-\mathrm{C}$ alloys but such information was found to be very meagre. The situation was improved by accepting that a single equation can be used for $B_{\mathrm{S}}$ and corresponding information for Widmanstätten ferrite, $W_{\mathrm{S}}$. The resulting equation had some support from information on plain carbon steels, covering a wide range of temperatures.

Accepting the new equation for Fe-C alloys it was then possible to evaluate the effect of alloying elements one by one from ternary information. The best ternary information was found for Fe-C-Mn alloys. For Fe-C-Si alloys there were two conflicting sets of information and additional information on $\mathrm{Fe}-\mathrm{C}-\mathrm{Mn}-\mathrm{Si}$ alloys was employed in the final decision. Information on Fe-C$\mathrm{Cr}, \mathrm{Fe}-\mathrm{C}-\mathrm{Mo}$ and $\mathrm{Fe}-\mathrm{C}-\mathrm{Ni}$ alloys were also analyzed.

The results were summarized in a linear equation which was tested by application to a large survey of information from Kolmskog et al. ${ }^{[12]}$ It was divided in two groups concerning the measurement of the critical temperature where bainite starts forming, the T method, or the critical carbon content where bainite stops forming, the $\mathrm{C}$ method. Those authors used the classical equation by Steven and Haynes ${ }^{[1]}$ and found that there was not a significant difference between the two groups and most of the scatter was due to experimental scatter. That was now confirmed when the new equation was applied to the two groups of information. It seems that the new equation is only slightly better than the classical one in applications to alloyed steels in general. On the other hand, it is most probably superior for estimating the effects of individual alloying elements. Further improvement is called for and would depend critically on better information on binary $\mathrm{Fe}-\mathrm{C}$ alloys but also on less experimental scatter for ternary alloys.

\section{ACKNOWLEDGMENTS}

Open access funding provided by Royal Institute of Technology. This study was conducted within the VINN Excellence center Hero-m and Competence center Hero-m 2 Innovation. The authors would like to thank Hossein Ehteshami for discussions. The authors acknowledge the financial support provided by VINNOVA, the Swedish Governmental Agency for Innovation Systems, Swedish industry and KTH Royal Institute of Technology.

\section{OPEN ACCESS}

This article is distributed under the terms of the Creative Commons Attribution 4.0 International License (http://creativecommons.org/licenses/by/4.0/), which permits unrestricted use, distribution, and reproduction in any medium, provided you give appropriate credit to the original author(s) and the source, provide a link to the Creative Commons license, and indicate if changes were made.

\section{REFERENCES}

1. W. Steven and A.G. Haynes: J. Iron Steel Inst., 1956, vol. 183, pp. 349-59.

2. S. Kang, S. Yoon, and S.-J. Lee: ISIJ Int., 2014, vol. 54, pp. 997-99.

3. J.S. Kirkaldy and G Venugopalan: in Phase Transformations in Ferrous Alloys, A.R. Marder and J.I. Goldstein, eds., TMS AIME, Warrendale, PA, 1984, p. 125.

4. M. Suehiro, T. Senuma, H. Yada, Y. Matsumura, and T. Ariyoshi: Tetsu-to-Hagané, 1987, vol. 73, pp. 1026-33.

5. R.L. Bodnar, T. Ohashi, and R.I. Jaffee: Metall. Trans. A, 1989, vol. 20A, pp. 1445-60.

6. J. Zhao and Z. Jin: Mater. Sci. Techn., 1992, vol. 8, pp. 1004-10. 
7. T. Kunitake and Y. Okada: J. Iron Steel Japan, 1998, vol. 84, pp. 137-41.

8. J.K. Lee, Prediction of Tensile Deformation Behavior of Formable Hot Rolled steels. POSCO Technical Research Laboratories Report, POSCO, Pohang, Korea, 1999.

9. J. Zhao, C. Liu, Y. Liu, and D.O. Northwood: J. Mater. Sci., 2001, vol. 36, pp. 5045-56.

10. Y.K. Lee: J. Mater. Sci., 2002, vol. 21, pp. 1253-55.

11. S.M.C. van Bohemen: Mater. Sci. Techn., 2012, vol. 28, pp. 487-95.

12. P. Kolmskog, L. Leach, L. Höglund, M. Hillert and A. Borgenstam: Comparison of Critical Temperature and Critical Carbon Content of Bainite Formation. (to be published).

13. M. Hillert: The Growth of Ferrite, Bainite and Martensite, Report, Swedish Inst. Metal Research, 1960. Printed in Thermodynamics and Phase Transformations, The Selected Works of Mats Hillert, eds. J. Ågren, Y. Bréchet, C. Hutchinson, J. Philibert and G. Purdy, EDP Science, Les Ulis Cedex, France, 2006.

14. T. Lyman and A.R. Troiano: Trans. ASM, 1946, vol. 37, pp. $402-48$.

15. J.O. Andersson, T. Helander, L. Höglund, P. Shi, and B. Sundman: Calphad, 2002, vol. 26, pp. 273-312.

16. Thermo-Calc: TCFE8-TCS Steels/Fe-Alloys Database, v8.0, 2015. http://www.thermocalc.com. Accessed 2017.

17. H.I. Aaronson: in Decomposition of Austenite by Diffusional Processes, V.F. Zackay and H.I. Aaronson, eds., Interscience, New York, 1962, pp. 387-546.

18. S.E. Johanson, Thesis, KTH, Stockholm 1959. Quoted in Ref. 13.

19. R.D. Townsend and J.S. Kirkaldy: Trans. ASM, 1968, vol. 61, pp. $605-19$.

20. H.I. Aaronson, P.G. Boswell, and K.R. Kinsman: in Mechanical Properties and Phase Transformations in Engineering Materials-Earl L. Parker Symposiumon Structure Property Relationships TMS-AIME, Warrendale, PA (1986), pp. 467-73.

21. Z.Q. Liu, G. Miyamoto, Z.G. Yang, and T. Furuhara: Acta Mater., 2013, vol. 61, pp. 3120-29.

22. Z.Q. Liu, G. Miyamoto, Z.G. Yang, C. Zhang, and T. Furuhara: Metall. Mater. Trans. A, 2015, vol. 46A, pp. 1544-49.

23. A. Borgenstam, KTH Royal Institute of Technology, Stockholm, Sweden, Unpublished Research, 2005.

24. A. Hultgren: Trans. ASM, 1947, vol. 39, pp. 915-89.

25. M. Hillert: KTH, Royal Institute of Technology, Stockholm, Sweden, Unpublished Research, 1970.
26. S.K. Liu, L. Yang, D.G. Zhu, and J. Zhang: Metall. Mater. Trans. A, 1994, vol. 25A, pp. 1991-2000.

27. A. Hultgren: Jernkont. Ann., 1951, vol. 135, pp. 403-94.

28. K. Tsuzaki, K. Fujiwara, and T. Maki: Mater. Trans., 1991, vol. 8, pp. $667-78$.

29. M. Umemoto and I. Tamura: Acta Metall., 1986, vol. 34, pp. $2235-45$.

30. A. Borgenstam and J.M. Ericsson: in Solid-to-Solid Phase Transformations in Inorganic Materials 2005, J.M. Howe, D.E. Laughlin, J.K. Lee, U. Dahmen, and W.A. Soffa, eds., TMS, Warrendale, 2005, pp. 105-10.

31. J.V. Bee, R.W.K. Honeycombe, and P.R. Howell: Metall. Trans. A, 1979, vol. 10A, pp. 1207-12.

32. H.K.D.H. Bhadeshia, in Solid-to-Solid Phase Transformations 1981, H.I. Aaronson, D.E. Laughlin, R.F. Sekerka, C.M. Wayman, eds., TMS-AIME, Pittsburgh, 1981, pp. 1041-48.

33. H. Goldenstein and H.I. Aaronson: Metall. Trans. A, 1990, vol. 21A, pp. 1465-78.

34. F.G. Berry and R.W.K. Honeycombe: Metall. Trans., 1970, vol. 1, pp. $3279-86$.

35. H. Tsubakino and H.I. Aaronson: Metall. Trans. A, 1987, vol. 18A, pp. 2047-60.

36. G.J. Shiflet and H.I. Aaronson: Metall. Trans. A, 1990, vol. 21A, pp. 1413-32.

37. W.T. Reynolds, Jr, F.Z. Li, C.K. Shui, and H.I. Aaronson: Metall. Trans. A, 1990, vol. 21A, pp. 1433-63.

38. W.T. Reynolds, Jr, S.K. Liu, F.Z. Li, S. Hartfield, and H.I. Aaronson: Metall. Trans. A, 1990, vol. 21A, pp. 1479-91.

39. K.M. Wu and M. Enomoto: Scripta Mater., 2002, vol. 46, pp. 569-74.

40. M. Enomoto: Scripta Mater., 2002, vol. 47, pp. 145-49.

41. L.M. Pevzner, T.D. Kubyushina, G.M. Rovenskii, and A.I. Samoilov: Soviet Metallogr. Treat. Met., 1956, vol. 11, pp. 2-20.

42. G. Papadimitriou and J.M.R. Genin: Mater. Res. Soc, 1983, vol. 21 , pp. $747-74$.

43. N. Usui, K. Sugimoto, E. Nishida, M. Kobayashi, and S. Hashimoto: CAMP-ISIJ, 1990, vol. 3, pp. 2013-14.

44. K. Sugimoto, J. Sakaguchi, T. Iida, and T. Kashima: ISIJ Int., 2000, vol. 40, pp. 920-26.

45. K. Sugimoto, K. Nakano, S. Song, and T. Kashima: ISIJ Int., 2002, vol. 42, pp. 450-55.

Publisher's Note Springer Nature remains neutral with regard to jurisdictional claims in published maps and institutional affiliations. 